\title{
Prolonged ventilation post cardiac surgery - tips and pitfalls of the prediction game
}

\author{
Piotr Knapik*, Daniel Ciesla, Dawid Borowik, Piotr Czempik and Tomasz Knapik
}

\begin{abstract}
Background: Few available models aim to identify patients at risk of prolonged ventilation after cardiac surgery. We compared prediction models developed in ICU in two adjacent periods of time, when significant changes were observed both in population characteristics and the perioperative management.

Methods: We performed a retrospective review of two cohorts of patients in our department in two subsequent time periods (July 2007 - December 2008, $n=2165$; January 2009 - July 2010, $n=2192$ ). The study was approved by the Institutional Ethics Committee and the individual patient consent was not required. Patients were divided with regard to ventilation time of more or less than 48 hours. Preoperative and procedure-related variables for prolonged ventilation were identified and multivariate logistic regression analysis was performed separately for each cohort.
\end{abstract}

Results: Most recent patients were older, with more co-morbidities, more frequently undergoing off-pump surgery. At the beginning of 2009 we also changed the technique of postoperative ventilation. Percentage of patients with prolonged ventilation decreased from 5.7\% to 2.4\% ( $p<0.0001)$.Preoperative and procedure-related variables for prolonged ventilation were identified. Prediction models for prolonged ventilation were different for each cohort. Most recent significant predictors were: aortic aneurysm surgery (OR 12.9), emergency surgery (OR 5.3), combined procedures (OR 5.1), valve procedures (OR 3.2), preoperative renal dysfunction (OR 2.9) and preoperative stroke or TIA (OR 2.8).

Conclusions: Prediction models for postoperative ventilation should be regularly updated, particularly when major changes are noted in patients' demographics and surgical or anaesthetic technique.

\section{Background}

Patients whose ventilation after cardiac surgery is unexpectedly prolonged are prone to a larger number of complications and higher mortality [1]. Additionally, they may present a practical problem for the regular activity of the postoperative intensive care unit.

In the simplest terms, it can be assumed that up to a certain time limit (usually covering a period of 12-24 hours), the duration of mechanical ventilation may depend on unique characteristics, the type of surgical procedure and local protocols within the individual postoperative ICU. In some ICUs, patients are usually extubated very early, even in the operating theatre, while in others - significantly later [2-6]. Attempts to reduce the time of postoperative ventilation may yield medical and financial benefits, however the early risk of hypothermia, bleeding and cardiorespiratory instability may sometimes outweigh

\footnotetext{
* Correspondence: pknapik@sum.edu.pl

Department of Cardiac Anaesthesia and Intensive Care, Silesian Centre for Heart Diseases, Zabrze, Poland
}

the potential benefits [2]. Time of postoperative ventilation depends on many factors [7-9], extubation criteria may vary between departments, and finally - early extubation may be dependent on the technique of anaesthesia [2] or sedation [7].

After the passage of 48 hours, only patients with serious, non-transient issues should remain ventilated. This is often due to general health problems, already present prior to surgery.

EuroSCORE is known to correlate with an extended ICU stay but extended ICU stay may be sometimes not associated with prolonged ventilation [10,11]. Additional differences may be population or learning curve-related [12].

During routine departmental audit we noticed that the percentage of patients with prolonged ventilation, remaining at a fairly constant level in our centre for many years, suddenly in 2009 dropped sharply by half. The same audit revealed, that at the same time we started to operate on more elderly patients (trying to avoid cardiopulmonary 
bypass if possible) and we also changed the technique of postoperative ventilation. We therefore decided to find out, how the prediction model of prolonged postoperative ventilation change within the same postoperative ICU in two adjacent and relatively short periods of time, when a number of significant changes are observed both in population characteristics and the perioperative management.

In the literature, there are various available models, predicting the occurrence of postoperative complications. They are mainly developed in a single institution, therefore they might not apply to other centers. No attempts have been made, however, to determine why the prediction models sometimes vary so much among themselves and what is the practical solution to this problem. The aim of our study was to examine how the prediction model of prolonged postoperative ventilation can change within the same postoperative ICU in two adjacent and relatively short periods of time, when a number of significant changes were observed both in population characteristics and the perioperative management.

\section{Methods}

We performed a retrospective review of all patients in our prospective departmental adult cardiac surgical database in two subsequent 18-month periods (first cohort: July 2007 - December 2008; second cohort: January 2009 - July 2010). The study was approved by the Institutional Ethics Committee and the individual patient consent was not required. The study was carried out in a tertiary care university hospital.

In our database, patients were classified according as: "coronary" (on pump or off pump), "valve" (single or more, replacement or repair), "combined" ("coronary" + "valve"), "aneurysm" (open repair only), "transplant" and "other" (various procedures, not able to create a homogenous group of at least 20 cases per year).

Patients in the categories "transplant" and "other" and 21 patients who died within 48 hours of surgery were excluded from the analysis. All the remaining 4,357 consecutive patients $(2,165$ in the first cohort and 2,192 in the second cohort) were included in the analysis.

"Unstable course of the disease" indicated patients with recent deterioration due to their cardiac disease. "Critical preoperative state" was reserved for patients on inotropic, mechanical and/or ventilatory support.

"Non-elective surgery" indicated that patients were required to stay in the hospital but could be planned and operated on within a normal schedule. "Emergency surgery" indicated patients with ongoing refractory cardiac compromise, unresponsive to other forms of therapy except for cardiac surgery. All patients who did not fulfill these definitions were considered to be "elective" (Table 1).

Patients in both cohorts were then divided into patients ventilated 48 hours or less, and patients ventilated more than 48 hours. In patients who were extubated and later required reintubation, the time of postoperative ventilation was added, which usually qualified them into the "prolonged ventilation" group.

Departmental criteria for extubation included: haemodynamic stability, lack of significant arrhythmias, minimal drainage $\left(<100 \mathrm{~mL} \cdot \mathrm{h}^{-1}\right)$ and postoperative pain, normal neurological status (absence of neurological deficit and full consciousness), oxygen saturation $>95 \%$ with fraction of inspired oxygen $<0.5$, oesophageal temperature $>36.0^{\circ} \mathrm{C}$ and respiratory rate of more than $12 / \mathrm{min}$. with no signs of respiratory distress. The decision regarding extubation was always undertaken by a physician in charge. Postoperatively, the patients were sedated with either intermittent bolus doses of midazolam or with propofol infusion. Intravenous injections of morphine were used to control postoperative pain.

Preoperative risk assessment was performed on the basis of standard (additive) EuroSCORE and patients were classified as carrying low ( $0-2$ points), moderate (3-5 points) or high risk (6 or more points). Additionally, logistic Euroscore was calculated for each patient since the standard Euro SCORE can underestimate mortality in high-risk patients [13].

Numerical data are shown by mean and standard deviation and compared with Mann-Whitney test. Binary data are shown as numbers and a percentages and compared with the use of the $\chi^{2}$ test with Yates correction, where appropriate. Independent preoperative variables that could affect postoperative ventilation time were identified and are listed in Table 2. The effect of independent variables on the outcome variable of interest (prolonged ventilation) was calculated with the use of multivariate logistic regression. Variables with $\mathrm{p}$ value $<0.05$ were then included in the multivariate logistic regression analysis, where $\mathrm{p}<0.05$ was considered significant.

\section{Results}

In comparison to the first cohort, patients in the second cohort were more frequently aged over 65 years, with unstable course of their cardiac disease, and more frequently presented signs of congestive heart failure (NYHA class III or IV), while their mode of operation was more frequently urgent. The percentage of coronary revascularization performed off-pump increased from $27 \%$ to $40 \%$ $(\mathrm{p}<0.0001)$. Percentage of patients with prolonged ventilation decreased from $5.7 \%$ to $2.4 \%(\mathrm{p}<0.0001)$ (Table 1).

Preoperative status and the distribution of procedures performed in patients with standard and prolonged ventilation differed significantly in the entire population studied (Table 2).

Multivariate analysis revealed that the independent predictors for prolonged ventilation were different for the two cohorts (Figure 1). The most significant predictors (aortic 
Table 1 Comparison of patients' cohorts

\begin{tabular}{|c|c|c|c|c|c|c|}
\hline \multirow{2}{*}{$\begin{array}{l}\text { Group of variables } \\
\text { Demographic data and general condition }\end{array}$} & \multirow{2}{*}{$\begin{array}{l}\text { Variable } \\
\text { Age }>65 \text { years }\end{array}$} & \multicolumn{2}{|c|}{$\begin{array}{l}2007-2008 \\
(n=2165)\end{array}$} & \multicolumn{2}{|c|}{$\begin{array}{l}2009-2010 \\
(n=2192)\end{array}$} & \multirow{2}{*}{$\begin{array}{c}p \\
0.04\end{array}$} \\
\hline & & 897 & $(41 \%)$ & 977 & $(45 \%)$ & \\
\hline & Female gender & 711 & $(33 \%)$ & 696 & $(32 \%)$ & 0.44 \\
\hline & Unstable course of disease & 801 & $(37 \%)$ & 891 & $(41 \%)$ & 0.01 \\
\hline & Critical preoperative state & 9 & $(0.4 \%)$ & 8 & $(0.4 \%)$ & 0.78 \\
\hline \multirow[t]{6}{*}{ Circulatory function } & CCS class IV & 193 & $(8.9 \%)$ & 197 & (9\%) & 0.93 \\
\hline & NYHA class III or IV & 344 & $(16 \%)$ & 464 & $(21 \%)$ & $<0.01$ \\
\hline & Previous PTCA/stent & 527 & $(24 \%)$ & 562 & $(26 \%)$ & 0.32 \\
\hline & Recent Ml up to 90 days & 395 & $(18 \%)$ & 328 & $(15 \%)$ & $<0.01$ \\
\hline & $E F<40 \%$ & 233 & $(11 \%)$ & 267 & $(12 \%)$ & 0.14 \\
\hline & Endocarditis & 22 & $(1.0 \%)$ & 20 & $(0.9 \%)$ & 0.72 \\
\hline \multirow[t]{8}{*}{ Co-morbidities } & Diabetes & 638 & $(30 \%)$ & 582 & $(27 \%)$ & 0.03 \\
\hline & Arterial hypertension & 1555 & $(72 \%)$ & 1713 & $(78 \%)$ & $<0.01$ \\
\hline & $\mathrm{BMI}>35$ & 106 & $(5 \%)$ & 99 & $(5 \%)$ & 0.78 \\
\hline & Renal failure & 46 & $(2 \%)$ & 56 & $(3 \%)$ & 0.35 \\
\hline & COPD & 214 & $(10 \%)$ & 193 & $(9 \%)$ & 0.22 \\
\hline & History of TIA or stroke & 133 & $(6 \%)$ & 125 & $(6 \%)$ & 0.54 \\
\hline & Carotid disease & 248 & $(12 \%)$ & 289 & $(13 \%)$ & 0.08 \\
\hline & Peripheral vascular disease & 312 & $(14 \%)$ & 308 & $(14 \%)$ & 0.73 \\
\hline \multirow[t]{10}{*}{ Procedure -related variables } & Previous cardiac surgery & 82 & $(4 \%)$ & 78 & $(4 \%)$ & 0.69 \\
\hline & Non-elective surgery & 338 & $(16 \%)$ & 625 & $(29 \%)$ & $<0.01$ \\
\hline & Emergency surgery & 62 & $(3 \%)$ & 75 & $(3 \%)$ & 0.29 \\
\hline & CABG & 783 & $(36 \%)$ & 412 & $(19 \%)$ & $<0.01$ \\
\hline & OPCAB/MIDCAB & 576 & $(27 \%)$ & 876 & $(40 \%)$ & $<0.01$ \\
\hline & $\mathrm{CPB}>2 \mathrm{~h}$ & 532 & $(25 \%)$ & 444 & $(20 \%)$ & $<0.01$ \\
\hline & Coronary surgery & 1359 & $(63 \%)$ & 1288 & $(59 \%)$ & 0.01 \\
\hline & Valve surgery & 500 & $(23 \%)$ & 577 & $(26 \%)$ & 0.01 \\
\hline & Combined procedures & 206 & $(9.5 \%)$ & 218 & $(10 \%)$ & 0.63 \\
\hline & Aortic aneurysm surgery & 100 & $(4.6 \%)$ & 109 & $(5.0 \%)$ & 0.58 \\
\hline
\end{tabular}

aneurysm surgery, emergency surgery, combined procedures, valve procedures) remained in their ranking order, however some of the previous significant predictors (age $>65$ years, NYHA class $>2$, urgent surgery and CABG) were no longer present in the new model.

On the basis of multivariate logistic regression models we developed a scoring scale (in points) assessing the risk of prolonged ventilation for the first cohort. Then, for each group of patients with the same number of points (separately in the first and second cohort) we determined the actual risk of prolonged ventilation and draw the curves of the risk of prolonged ventilation for the different scoring results. As it may be seen, scoring system for the first cohort clearly overestimated a risk of prolonged ventilation, when used in a second cohort (Figure 2).

\section{Discussion}

The results of our study indicate, that our population and patients' management constantly evolves. Our most recent patients are older, have more co-morbidities, and are more frequently undergoing off-pump surgery. In a most recent cohort, significant predictors for prolonged ventilation were aortic aneurysm surgery, combined procedures, valve procedures, preoperative renal dysfunction and preoperative stroke.

Cardiothoracic centres perform a considerable number of highly repetitive procedures. Together with a well organized local database, this may provide a solid basis for the application of various predictive models for all types of postoperative complications (neurological, respiratory, cardiovascular, infectious) or death. The literature abounds in various prediction models for postoperative complications, but their analysis may be quite confusing.

Prolonged ventilation is variably defined. It may be classified as postoperative ventilation continued for more than 12 hours [14], 24 hours [15,16], 48 hours [17], 72 hours [18], or even 96 hours after the operation [19]. Not surprisingly then, the results obtained may be contradictory and of very limited practical applicability.

What is more, authors tend to narrow down the groups of subjects, creating predictive models for prolonged ventilation in patients after one type of procedure only - for 
Table 2 Comparison of all patients with normal and prolonged ventilation

\begin{tabular}{|c|c|c|c|c|c|c|}
\hline \multirow{2}{*}{$\begin{array}{l}\text { Group of variables } \\
\text { Demographic data and general condition }\end{array}$} & \multirow{2}{*}{$\begin{array}{l}\text { Variable } \\
\text { Age }>65 \text { years }\end{array}$} & \multicolumn{2}{|c|}{$\begin{array}{l}\text { Normal ventilation } \\
\quad(n=4182)\end{array}$} & \multicolumn{2}{|c|}{$\begin{array}{c}\text { Prolonged } \\
\text { ventilation } \\
(n=175)\end{array}$} & \multirow{2}{*}{$\begin{array}{c}p \\
<0.01\end{array}$} \\
\hline & & 1780 & $(43 \%)$ & 94 & $(54 \%)$ & \\
\hline & Female gender & 1329 & $(32 \%)$ & 78 & $(45 \%)$ & $<0.01$ \\
\hline & Unstable course of disease & 1594 & $(38 \%)$ & 98 & $(56 \%)$ & $<0.00$ \\
\hline & Unstable course of disease & 1594 & $(38 \%)$ & 98 & $(56 \%)$ & $<0.01$ \\
\hline & Critical preoperative state & 8 & $(0.2 \%)$ & 9 & $(5.1 \%)$ & $<0.00$ \\
\hline & Critical preoperative state & 8 & $(0.2 \%)$ & 9 & $(5.1 \%)$ & $<0.01$ \\
\hline \multirow[t]{6}{*}{ Circulatory function } & CCS class IV & 366 & $(8.8 \%)$ & 24 & $(14 \%)$ & 0.02 \\
\hline & NYHA class III or IV & 740 & $(18 \%)$ & 68 & $(39 \%)$ & $<0.01$ \\
\hline & Previous PTCA/stent & 1053 & $(25 \%)$ & 36 & $(21 \%)$ & 0.17 \\
\hline & Recent MI up to 90 days & 694 & $(17 \%)$ & 29 & $(17 \%)$ & 0.99 \\
\hline & $E F<40 \%$ & 467 & $(11 \%)$ & 33 & (19\%) & $<0.01$ \\
\hline & Endocarditis & 37 & $(0.9 \%)$ & 5 & $(2.9 \%)$ & 0.03 \\
\hline \multirow[t]{8}{*}{ Co-morbidities } & Diabetes & 1164 & $(28 \%)$ & 56 & $(32 \%)$ & 0.23 \\
\hline & Arterial hypertension & 3149 & $(75 \%)$ & 119 & $(68 \%)$ & 0.03 \\
\hline & $\mathrm{BMI}>35$ & 196 & $(4.7 \%)$ & 9 & $(5.1 \%)$ & 0.78 \\
\hline & Renal failure & 92 & $(2.2 \%)$ & 10 & $(5.7 \%)$ & 0.01 \\
\hline & COPD & 389 & $(9.3 \%)$ & 18 & $(10 \%)$ & 0.66 \\
\hline & History of TIA or stroke & 235 & $(5.6 \%)$ & 23 & $(13 \%)$ & $<0.01$ \\
\hline & Carotid disease & 511 & $(12 \%)$ & 26 & $(15 \%)$ & 0.30 \\
\hline & Peripheral vascular disease & 599 & $(14 \%)$ & 21 & $(12 \%)$ & 0.39 \\
\hline \multirow[t]{13}{*}{ Procedure -related variables } & Previous cardiac surgery & 142 & $(3.4 \%)$ & 18 & $(10 \%)$ & $<0.01$ \\
\hline & Non-elective surgery & 922 & $(22 \%)$ & 41 & $(23 \%)$ & 0.67 \\
\hline & Emergency surgery & 104 & $(2.5 \%)$ & 33 & $(19 \%)$ & $<0.01$ \\
\hline & CABG & 1157 & $(28 \%)$ & 38 & $(22 \%)$ & 0.08 \\
\hline & OPCAB/MIDCAB & 1432 & $(34 \%)$ & 20 & $(11 \%)$ & $<0.01$ \\
\hline & $\mathrm{CPB}>2 \mathrm{~h}$ & 868 & $(21 \%)$ & 108 & $(62 \%)$ & $<0.00$ \\
\hline & $\mathrm{CPB}>2 \mathrm{~h}$ & 868 & $(21 \%)$ & 108 & $(62 \%)$ & $<0.01$ \\
\hline & Coronary surgery & 2589 & $(62 \%)$ & 58 & $(33 \%)$ & $<0.00$ \\
\hline & Coronary surgery & 2589 & $(62 \%)$ & 58 & $(33 \%)$ & $<0.01$ \\
\hline & Valve surgery & 1026 & $(25 \%)$ & 51 & $(29 \%)$ & 0.17 \\
\hline & Combined procedures & 388 & $(9.3 \%)$ & 36 & $(21 \%)$ & $<0.01$ \\
\hline & Aortic aneurysm surgery & 179 & $(4.3 \%)$ & 30 & $(17 \%)$ & $<0.00$ \\
\hline & Aortic aneurysm surgery & 179 & $(4.3 \%)$ & 30 & $(17 \%)$ & $<0.01$ \\
\hline Outcome & Death & 28 & $(0.7 \%)$ & 47 & $(27 \%)$ & $<0.01$ \\
\hline
\end{tabular}

example, after coronary revascularisation with cardiopulmonary bypass $[14,15]$, adult valve procedures $[16,20]$,or aortic aneurysm surgery [17]. The only benefit of this approach is the increased homogeneity of the studied group.

Mean extubation times were not the focus of this study. The primary objective was to obtain a practical possibility of predicting a successful execution of a theatre plan taking into account a limited number of intensive beds. It is well known that a patient whose ventilation takes longer than 48 hours, will constitute not only a medical, but also an organizational challenge for the department.

Originally, our intention was to develop a prediction model based on a large population of patients operated on between 2007 and 2010, on the basis of approximately 6,000 patients. Quite surprisingly, however, it turned out that the percentage of patients with prolonged ventilation (>48 hours), which for many years (2004-2008) remained at a fairly constant level (approximately $5 \%$ ), suddenly in 2009 dropped sharply by half (to $2.5 \%$ ), reaching values lower than those reported by authors of comparable reports [21]. More interestingly, the characteristics of patients also changed - in a more recent period, there were more elderly patients, with many co-morbitities. The surgical technique also changed - in a subgroup of patients undergoing coronary revascularization, an almost two-fold increase was observed in the percentage of procedures performed without cardiopulmonary bypass (from $37 \%$ to 


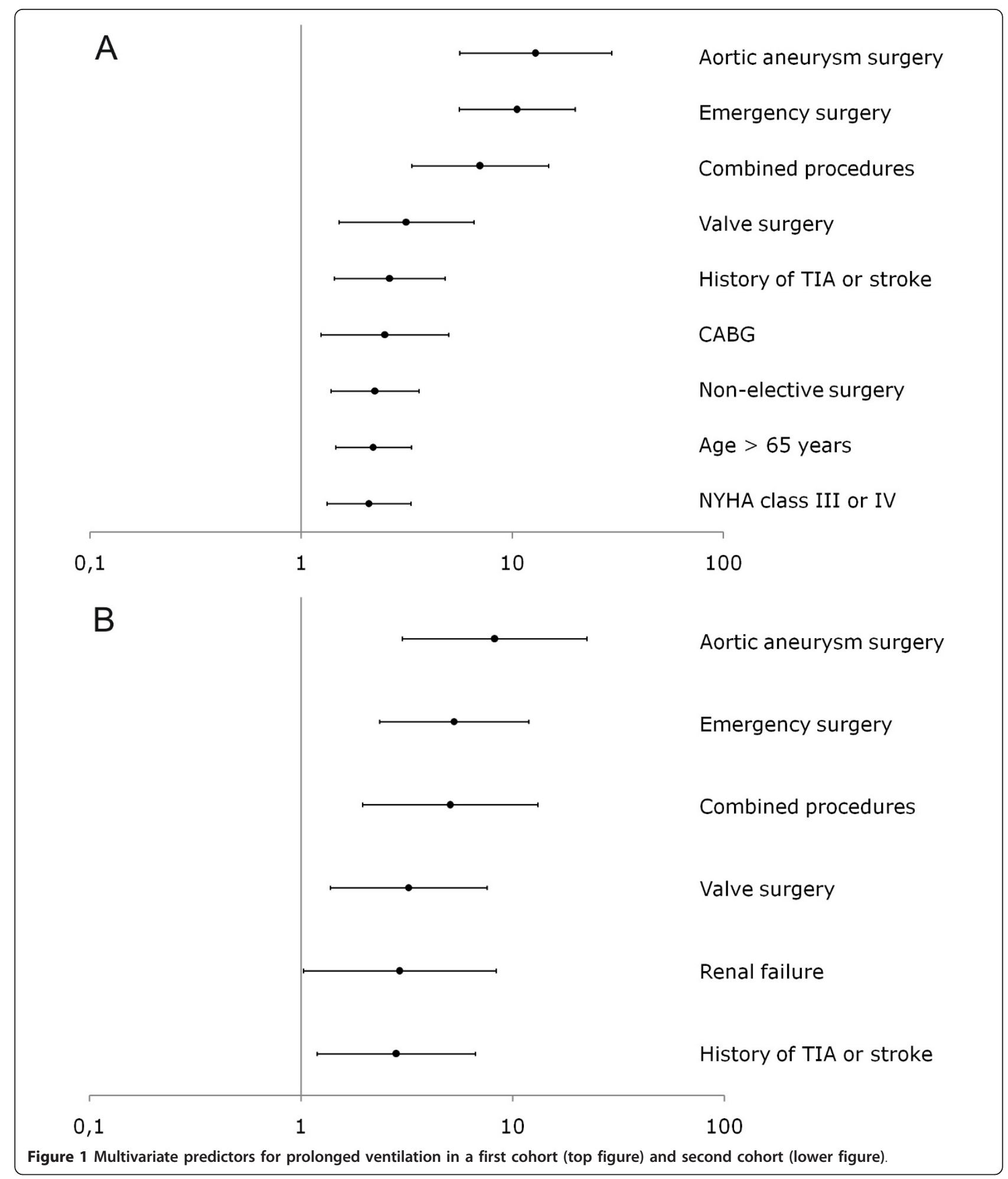

$68 \%$ ). Finally, also in 2009 , we changed the technique of postoperative ventilation, introducing a lung protective strategy with higher end-expiratory pressures (PEEP) and smaller tidal volumes for all operated patients, although this method is not aimed primarily at patients with healthy lungs [22]. Tidal volumes were reduced from $7-8 \mathrm{ml} / \mathrm{kg}$ to $5-6 \mathrm{ml} / \mathrm{kg}$, whilst PEEP levels were increased from $0-3 \mathrm{~cm}$ $\mathrm{H} 2 \mathrm{O}$ to $6-8 \mathrm{~cm} \mathrm{H}_{2} \mathrm{O}$. Additionally, patients started to be 


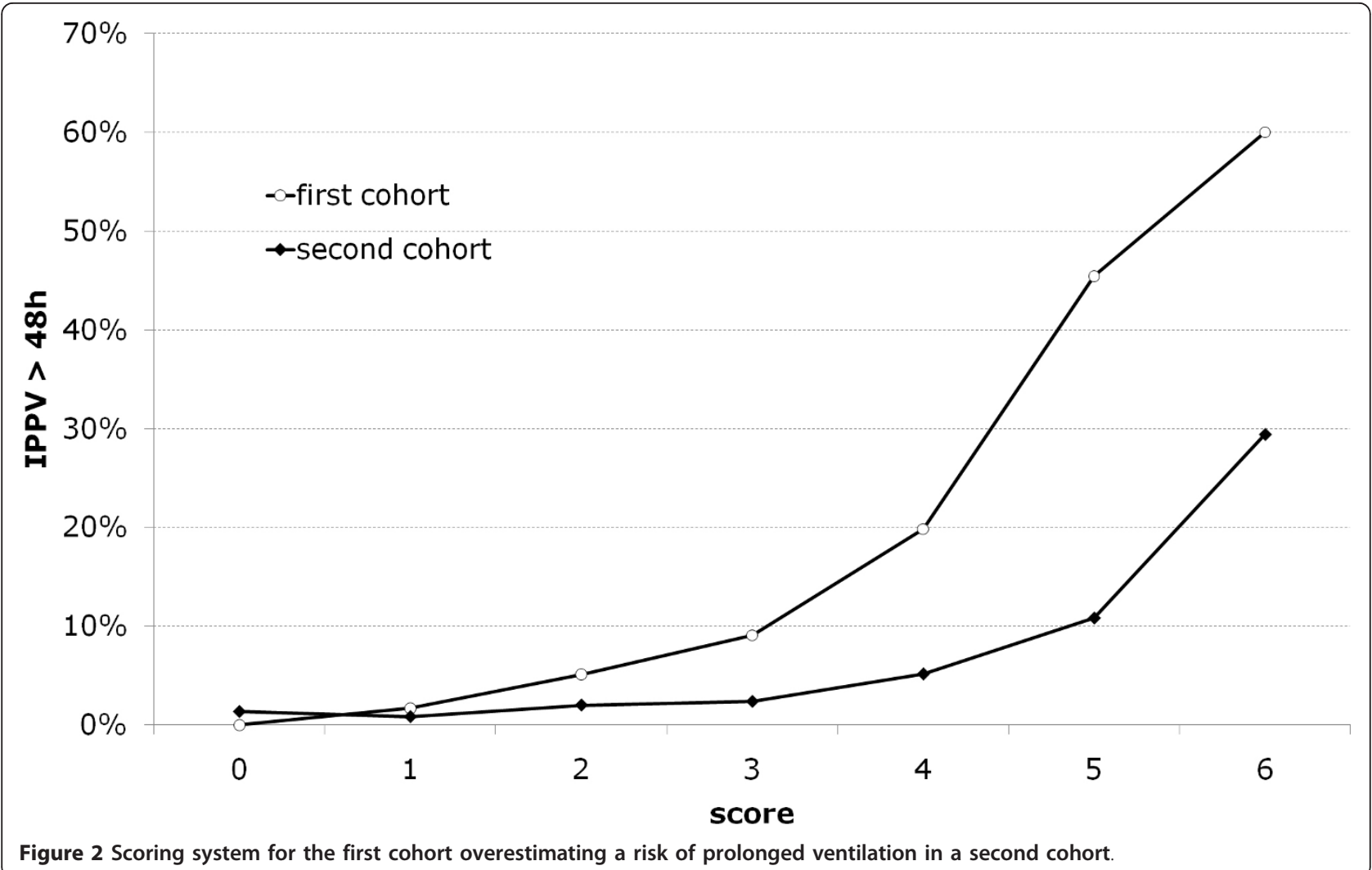

extubated directly from the ventilator, without a spontaneous breathing trial.

If we had analyzed in detail the differences between the periods of 2007-2008 and 2009-2010, we would probably have identified an even greater number of more or less important differences. This is not surprising, as this phenomenon occurs in every department - medical care continually evolves, changes are made, and the team climbs higher and higher in their skills as per the learning curve principle. The consequence of all these changes, however, is that the prediction models developed for a specific period of time may prove out of date, as was the case with prolonged ventilation. The model developed in 20072008 was not very useful for the population of patients operated on in 2009 and 2010.

Comparing the prediction models from 2007-2008 and 2009-2010, we found some very interesting relationships. It turned out that the most important predictors (in order - aortic aneurysm surgery, emergency surgery, complex procedures and valve procedures) remained in their places in the "ranking" of prediction, still significantly increasing the risk of prolonged ventilation. Some of the previous predictors, however, were missing namely, urgent operation, advanced age ( $>65$ years), presence of congestive heart failure (NYHA III or IV) and coronary revascularization with cardiopulmonary bypass.
The absence of these predictors in the new model may be logically explained. We have probably advanced more in the management of sick, elderly patients with overt heart failure. The percentage of urgent patients has increased from $15.6 \%$ to $28.5 \%$, so urgent surgery has become the rule rather than the exception. Coronary revascularization with cardiopulmonary bypass surgery (CABG technique) was once reserved for more difficult coronary patients, whilst more straightforward cases tended to be scheduled for OPCAB. Today, the trend has reversed and the OPCAB technique is now considered suitable for elderly patients with various co-morbidities [23].

In our department we are interested in a realistic prediction of postoperative complications. The ultimate goal is to identify predictors and to apply them in practice otherwise, it becomes art for art's sake. In accordance with these principles, our department has already introduced prediction models for renal replacement therapy, permanent neurological complications and prolonged ventilation ( $>48$ hours). Each model was developed with a different method.

The primary factor in determining how to conduct a given analysis is always an audit revealing the incidence of complications over the previous few years. Our audit showed that the fractions of patients undergoing renal 
replacement therapy, and patients who experienced permanent neurological complications, were fairly constant and averaged between $2.5 \%$ and $2.7 \%$ respectively, whilst the proportion of patients with prolonged ventilation decreased suddenly in the last two years (from 5\% to $2.5 \%)$.

For the prediction of renal replacement therapy, we reintroduced the 2007 model proposed by Wijeysundera et al., originally encompassing 20,131 Canadian patients [24]. When in 2008, it was concluded that the model worked very well also for the Polish population, it was introduced in our department. The model appears to be reliable, as the incidence of renal replacement therapy remains constant and, additionally, the demographic data of our patients seem to drift slowly towards the Canadian cohort [25].

For the prediction of permanent neurological complications, however, we decided to develop our own model, based on the analysis of our large cohort of 6,016 consecutive patients [26]. We were forced to ignore the existing models proposed in the literature, as they were inconsistent and resulted in conflicting results when tested on our population. We plan to use our model for at least another two years, as the incidence of permanent neurological injury in our department is also fairly constant. Both the above-presented models are likely to be subjected to routine verification in a couple of years, unless the data from internal audits indicate that the prevalence of any of these complications has suddenly changed.

Therefore, in the prediction of prolonged ventilation, we had to choose another solution. We decided to introduce a model based on an analysis of data derived only from the 2009-2010 period (due to the recent sudden decline in the proportion of patients with prolonged ventilation).

What is going to happen next? Does this mean that over the next few years, in predicting prolonged ventilation, we will be using the model based on the analysis of 2,192 patients only?

We do not know yet; the answer depends on the situation! In 2012 we plan to check whether the proportion of patients requiring prolonged ventilation has set on a new, lower level or still continues to change. If this proportion proves to be permanent - we will perform prospective validation of this model in a most recent population. If satisfactory, we will recalculate the data for a larger population (and thus for the entire period from 2008 to 2012) and to make the necessary corrections (which are likely to be minor). Otherwise, we will have to develop another model based on the previous two years ... unless, in the meantime, the medical literature offers us a better solution to this problem.

An important limitation of our study is in the retrospective data extraction, however a lot of work is carried out to confirm the high quality of the hospital database.
Another limitation of the study was the exclusion of all patients in the categories "transplant" and "other", but it is always very difficult to create predictive models on the basis of such non-homogenous groups.

The results of our study indicate, that prediction game is particularly prone to bias and misinterpretation and prediction models should be always approached with caution. Moreover, even centre-specific, departmental prediction models should be updated, when major changes are noted in patients' demographics or management.

\section{Acknowledgements}

We wish to thank Mrs Jolanta Cieśla for her help in preparing the manuscript.

\section{Authors' contributions}

PK conceived and planned the study and drafted an early, initial olan of the manuscript manuscript.

DC planned and performed statistical analysis, drafted specific part of the manuscript (figures, legends, statistical analysis).

DB performed literature search, drafted specific part of the manuscript, participated in the design and coordination.

PC performed extensive literature search and drafted specific part of the manuscript.

TK performed extensiveliterature search and drafted specific part of the manuscript.

All authors read and approved the final manuscript.

\section{Competing interests}

The authors declare that they have no competing interests.

Received: 11 July 2011 Accepted: 23 November 2011

Published: 23 November 2011

\section{References}

1. Pappalardo F, Franco A, Landoni G, Cardano P, Zangrillo A, Alfieri O: Longterm outcome and quality of life of patients requiring prolonged mechanical ventilation after cardiac surgery. Eur I Cardiothorac Surg 2004, 25:548-552.

2. Cheng D: Anesthetic techniques and early extubation: does it matter? J Cardiothorac Vasc Anesth 2000, 14:627-630.

3. Higgins TL: Pro: early endotracheal extubation is preferable to late extubation in patients following coronary artery surgery. $J$ Cardiothorac Vasc Anesth 1992, 6:488-493.

4. Oxelbark S, Bengtsson L, Eggersen M, Kopp J, Pedersen J, Sanchez R: Fast track as a routine for open heart surgery. Eur J Cardiothorac Surg 2001, 19:460-463.

5. Sato M, Suenaga E, Koga S, Matsuyama S, Kawasaki H, Maki F: Early tracheal extubation after on-pump coronary artery bypass grafting. Ann Thorac Cardiovasc Surg 2009, 15:239-242.

6. Straka Z, Brucek P, Vanek T, Votava J, Widimsky P: Routine immediate extubation for off-pump coronary artery bypass grafting without thoracic epidural analgesia. Ann Thorac Surg 2002, 74:1544-1547.

7. Oliver WC Jr, Nuttall GA, Murari T, Bauer LK, Johnsrud KH, Hall Long KJ, Orszulak TA, Schaff HV, Hanson AC, Schroeder DR, Ereth MH, Abel MD: A Prospective, Randomized, Double-Blind Trial of 3 Regimens for Sedation and Analgesia After Cardiac Surgery. J Cardiothorac Vasc Anesth 2011, 25:110-119.

8. Hawkes C, Foxcroft DR, Yerrell P: Clinical guideline for nurse-led early extubation after coronary artery bypass: an evaluation. J Adv Nurs 2010, 66:2038-2049.

9. Hancock HC, Easen PR: The decision-making processes of nurses when extubating patients following cardiac surgery: an ethnographic study. Int J Nurs Stud 2006, 43:693-705.

10. Messaoudi N, De Cocker J, Stockman BA, Bossaert LL, Rodrigus IE: Is EuroSCORE useful in the prediction of extended intensive care unit stay after cardiac surgery? Eur J Cardiothorac Surg 2009, 36:35-39. 
11. Ettema RG, Peelen LM, Schuurmans MJ, Nierich AP, Kalkman CJ, Moons KG: Prediction models for prolonged intensive care unit stay after cardiac surgery: systematic review and validation study. Circulation 2010, 122:682-689.

12. Sayed S, Fischer S, Karck M, Hassouna A, Haverich A: Effect of different preoperative patient characteristics on coronary surgery outcome: a comparative study between a developing and a developed country. J Card Surg 2009, 24:275-280.

13. Roques F, Michel P, Goldstone AR, Nashef SA: The logistic EuroSCORE. Eur Heart J 2003, 24:882-883.

14. Cislaghi F, Condemi AM, Corona A: Predictors of prolonged mechanical ventilation in a cohort of 3,269 CABG patients. Minerva Anestesiol 2007, 73:615-621.

15. Natarajan K, Patil S, Lesley N, Ninan B: Predictors of prolonged mechanical ventilation after on-pump coronary artery bypass grafting. Ann Card Anaesth 2006, 9:31-36.

16. Shirzad M, Karimi A, Ahmadi SH, Marzban M, Tazik M, Aramin H: Predictors and early outcome of prolonged mechanical ventilation in contemporary heart valve surgery. Monaldi Arch Chest Dis 2010, 74:22-27.

17. Kimura N, Tanaka M, Kawahito K, Sanui M, Yamaguchi A, Ino T, Adachi H: Risk factors for prolonged mechanical ventilation following surgery for acute type a aortic dissection. Circ J 2008, 72:1751-1757.

18. Trouillet JL, Combes A, Vaissier E, Luyt CE, Ouattara A, Pavie A, Chastre J: Prolonged mechanical ventilation after cardiac surgery: outcome and predictors. J Thorac Cardiovasc Surg 2009, 138:948-953.

19. Rajakaruna C, Rogers CA, Angelini GD, Ascione R: Risk factors for and economic implications of prolonged ventilation after cardiac surgery. J Thorac Cardiovasc Surg 2005, 130:1270-1277.

20. Rodrigues AJ, Mendes V, Ferreira PE, Xavier MA, Augusto VS, Bassetto $S$, Evora PR: Preoperative respiratory muscle dysfunction is a predictor of prolonged invasive mechanical ventilation in cardiorespiratory complications after heart valve surgery. Eur J Cardiothorac Surg 2011, 39:662-666.

21. Reddy SL, Grayson AD, Griffiths EM, Pullan DM, Rashid A: Logistic risk model for prolonged ventilation after adult cardiac surgery. Ann Thorac Surg 2007, 84:528-536.

22. Beck-Schimmer B, Schimmer RC: Perioperative tidal volume and intraoperative open lung strategy in healthy lungs: where are we going? Best Pract Res Clin Anaesthesiol 2010, 24:199-210.

23. Tekumit H, Riza Cenal A, Tataroglu C, Polat A, Uzun K, Akinci E: Off-pump coronary artery bypass surgery can be completed safely in high risk patients. Kardiol Pol 2010, 68:166-172.

24. Wijeysundera DN, Karkouti K, Dupuis JY, Rao V, Chan CT, Granton JT, Beattie WS: Derivation and validation of a simplified predictive index for renal replacement therapy after cardiac surgery. JAMA 2007, 297:1801-1809.

25. Knapik P, Rozentryt P, Nadziakiewicz P, Polonski L, Zembala M: Retrospective cross-validation of simplified predictive index for renal replacement therapy after cardiac surgery. Interact Cardiovasc Thorac Surg 2008, 7:1101-1106.

26. Knapik P, Cieśla D, Wawrzyńczyk M, Knapik M, Borkowski J, Zembala M: Incidence and prediction of permanent neurological deficits after cardiac surgery - are the existing models of prediction truly global? Eur $J$ Cardiothorac Surg 2010, 37:717-723.

doi:10.1186/1749-8090-6-158

Cite this article as: Knapik et al:: Prolonged ventilation post cardiac surgery - tips and pitfalls of the prediction game. Journal of Cardiothoracic Surgery 2011 6:158.

\section{Submit your next manuscript to BioMed Central and take full advantage of:}

- Convenient online submission

- Thorough peer review

- No space constraints or color figure charges

- Immediate publication on acceptance

- Inclusion in PubMed, CAS, Scopus and Google Scholar

- Research which is freely available for redistribution

Submit your manuscript at www.biomedcentral.com/submit
Biomed Central 